\section{Sox2 is required for development of taste bud sensory cells}

\author{
Tadashi Okubo, ${ }^{1,3,5}$ Larysa H. Pevny, ${ }^{2}$ and \\ Brigid L.M. Hogan ${ }^{1,4}$
}

${ }^{1}$ Department of Cell Biology, Duke University Medical Center, Durham, North Carolina 27710, USA; ${ }^{2}$ Department of Genetics, University of North Carolina, Chapel Hill, North Carolina 27599, USA

Sox2 is expressed in basal epithelial cells of the tongue, with high levels in taste bud placodes, fungiform papillae, and mature taste cells, and low levels in filiform papillae. High Sox2 expression appears to lie downstream from canonical Wnt signaling. In hypomorphic Sox $2^{E G F P / L P}$ embryos, placodes form but no mature taste buds develop. In contrast, transgenic overexpression of Sox 2 in the basal cells inhibits differentiation of filiform keratinocytes. Together, our loss-of-function and gainof-function studies suggest that Sox 2 functions in a dosedependent manner to regulate the differentiation of endodermal progenitor cells of the tongue into taste bud sensory cells versus keratinocytes.

Supplemental material is available at http://www.genesdev.org.

Received June 8, 2006; revised version accepted August 18, 2006.

Sox2, a SoxB1-HMG-box transcription factor, is a critical player in mammalian development. It is essential for maintaining the pluripotent phenotype of mouse embryonic stem and epiblast cells (Avilion et al. 2003; Boyer et al. 2005) and is highly expressed in neural progenitors of the vertebrate CNS. In addition, Sox 2 is required for the development of sensory systems. For example, in progenitor cells of the retina, Sox2 functions downstream from Wnt signaling to control the choice between the multipotent, proliferative phenotype and differentiation along alternate lineages (Van Raay et al. 2005; Taranova et al. 2006). In the neuroepithelium of the inner ear, Sox2 is an upstream regulator of Math1 and required for the establishment of sensory hair cells (Kiernan et al. 2005). Here, we provide the first evidence that Sox 2 is required for the differentiation of endodermal progenitor cells of the mouse tongue into taste bud (TB) cells.

TBs are found in several locations in the oral cavity. On the tongue they are present at the top of the fungiform papillae and in clusters in the vallate and foliate papillae. They are also located in the posterior soft pal-

[Keywords: Sox2; taste bud; tongue; Wnt; transgenic; hypomorphic mu$\operatorname{tant}]$

${ }^{3}$ Present address: Center for Integrative Bioscience, National Institutes of Natural Sciences, Okazaki, Aichi 444-8787, Japan.

Corresponding authors.

${ }^{4}$ E-MAIL b.hogan@cellbio.duke.edu; FAX (919) 684-8592.

${ }^{5}$ E-MAIL t.okubo@nibb.ac.jp; FAX 81-564-59-5240.

Article is online at http://www.genesdev.org/cgi/doi/10.1101/gad.1457106. ate. Each mature TB consists of $\sim 50-100$ sensory receptor cells that transduce distinct chemical stimuli and a small number of basal cells (Delay et al. 1986). All these cell types ultimately arise from progenitor cells of the pharyngeal endoderm. These progenitors are likely bipotential since they also give rise to the differentiated keratinocytes of the numerous filiform papillae covering the tongue. Very little is known about the differentiation of tongue progenitors into keratinocytes and sensory cells. Likewise, it is unclear how the normal turnover and self-renewal of these two populations is controlled (Potten et al. 1977), although there is some evidence that sensory neurones can be renewed from the basal cells of TBs (Beidler and Smallman 1965).

Using an EGFP reporter allele (Taranova et al. 2006), we show that the basal epithelial cells of the developing mouse tongue express Sox2. Moreover, the TB cells, and the placodes and papillae from which they are derived, express higher levels of Sox2 than the surrounding epithelial cells. Based on both gain-of-function and loss-offunction experiments we propose a model in which Sox 2 regulates the differentiation of putative bipotential tongue endodermal cells into either keratinocytes or TB progenitors and differentiated taste receptor cells.

\section{Results and Discussion}

Expression of Sox $2^{E G F P}$ and protein during tongue development

The tongue primordium arises from the floor of the first and second branchial arches at embryonic day 11.5 (E11.5) and rapidly expands within the pharyngeal cavity. By E13-E14 rows of tightly packed epithelial cells that are the primordial placodes of the fungiform papillae appear on the antero-dorsal surface. During the papilla induction stage (E14-E16.5), interactions between these placodes and the underlying mesenchyme give rise to domelike fungiform papillae (Mistretta 1998). Subsequently, TBs differentiate as clusters of neuronal cells in the center of the papillae at around E18.5 to postnatal day $0(\mathrm{P0})$. Gustatory nerves first appear under the epithelium at E14.5 and are associated with papillae at E16.5, but TB cells are not fully innervated until E18.5 (Lopez and Krimm 2006). The timing of TB development differs somewhat in other regions; in the posterior (soft) palate they develop at E17.5, while in the vallate and foliate papillae they only form postnatally (P2-P3).

To follow Sox2 expression in relation to TB development, we used the Sox $2^{E G F P}$ knock-in reporter allele. EGFP is first detected in the surface epithelium of the tongue at E12.5, and by E13.5 is clearly expressed at higher levels in the developing fungiform papillae compared with the surrounding epithelium (Fig. 1A,B). Similar results were obtained by visualizing EGFP in frozen sections (Fig. 1C) and by immunohistochemistry with Sox2 antibody (Fig. 1D). Elevated Sox $2^{E G F P}$ continues to mark developing fungiform papillae at E17.5 (Fig. 1E). Postnatally, Sox $2^{E G F P}$ activity remains high in the fungiform papillae and palate (Fig. 1G,I,J; Supplementary Fig. 1). Moreover, analysis of cryosections confirms EGFP expression in apparently all differentiated TB cells (Fig. $1 \mathrm{H}, \mathrm{K}$ ). A similar dynamic pattern of Sox ${ }^{E G F P}$ ex- 

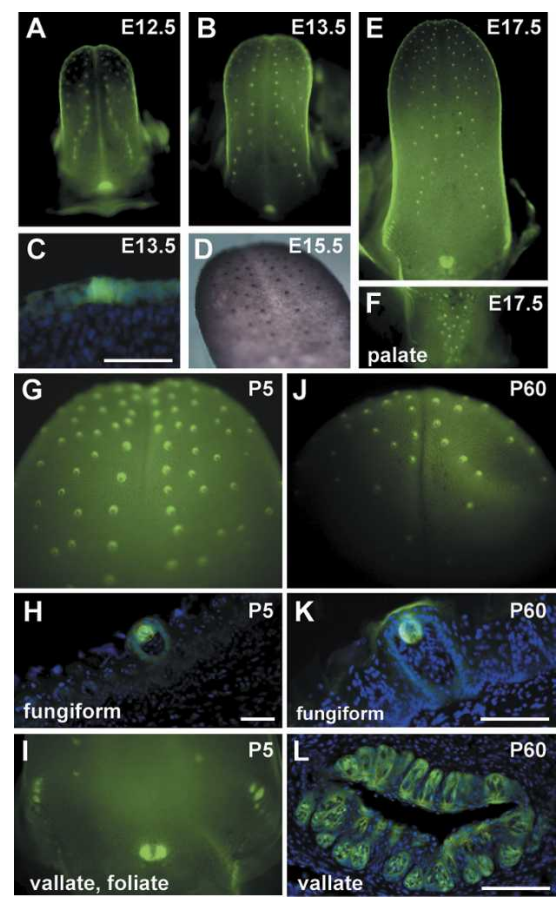

Figure 1. Sox 2 expression during $\mathrm{TB}$ development. Sox $2^{E G F P}$ expression in whole tongues at E12.5 $(A), \mathrm{E} 13.5(B)$, and E17.5 $(E)$, and in posterior palate at E17.5 $(F) .(C)$ Cryosection of E13.5 Sox $2^{E G F P /+}$ tongue shows fluorescence in columnar placode cells. $(D)$ Wholemount immunostaining for Sox2 in E15.5 tongue. Sox $2^{E G F P /+}$ tissues at P5 $(G-I)$ and P60 $(J-L)$ show expression in the intact anterior tongue $(G, J)$, and in cryosections of fungiform $(H, K)$, and vallate and foliate papillae $(I, L)$. The superficial fluorescence in $K$ is nonspecific. Bars: $C, H, 50 \mu \mathrm{m} ; K, L, 100 \mu \mathrm{m}$.

pression is seen during the development of the vallate, foliate papillae, and palate TBs (Fig. 1E,F,I). Even older mice (P60 to $9 \mathrm{mo}$ ) have strong Sox $2^{E G F P}$ signal in the vallate (Fig. 1L; Supplementary Fig. 1). In conclusion, Sox2 is expressed at low levels throughout the basal epithelium of the developing and adult mouse tongue and at high levels exclusively in TB progenitor cells and in mature taste receptor cells into adulthood.

\section{Absence of fungiform papillae and TBs in Sox2 hypomorphic mutants}

We investigated the tongue phenotype of hypomorphic Sox $2^{E G F P / L P}$ mutants, which express Sox2 at $\sim 20 \%$ of normal levels in the neuroepithelium of the developing eye (Taranova et al. 2006). A total of 207 embryos and pups were examined $\left(S_{0 x 2^{+/+}}, 54\right.$; Sox $2^{L P /+}, 53$; Sox2 $2^{E G F P /+}, 46$; Sox2 $\left.2^{E G P / L P}, 54\right)$; the phenotype of the Sox $2^{E G F P / L P}$ mutants was very reproducible. The Sox $2^{E G F P / L P}$ pups die soon after birth with abnormalities in the esophagus and stomach (T. Okubo, L.H. Pevny, and B.L.M. Hogan, unpubl.). There were no obvious defects in the initial number, morphology, and location of the fungiform papillae, but by E16.5-E18.5 there were far fewer of these structures in mutants compared with wild type (Supplementary Fig. 2). By P0 they were almost completely absent (Fig. 2A,B). Serial sectioning of tongues from three to four independent pups revealed $106 \pm 8.2$ TBs per wild-type tongue, compared with $6 \pm 0.8$ per $\operatorname{Sox} 2^{E G F P / L P}$ tongue $(p<0.001)$. We also examined sections of tongues at various stages after immunostaining for Sox2. At E18.5 to
P0, the wild-type tongue has well-developed fungiform papillae with higher expression of Sox 2 compared with the basal layer of keratinocytes (Fig. 2C,E,G). In contrast, Sox2 mutant tongues had no fungiform papillae (Fig. 2D,F,H). Histological analysis of mutant tongues at intermediate stages (E14.5-E18) showed a gradual reduction in the size and morphology of the fungiform papillae (Supplementary Fig. 2). Finally, we confirmed the absence of TBs in P0 mutant tongues by staining sections with antibodies to Keratin 8 (K8), a marker of mature TB cells (Knapp et al. 1995). K8 is clearly expressed in wild-type tongues (Fig.
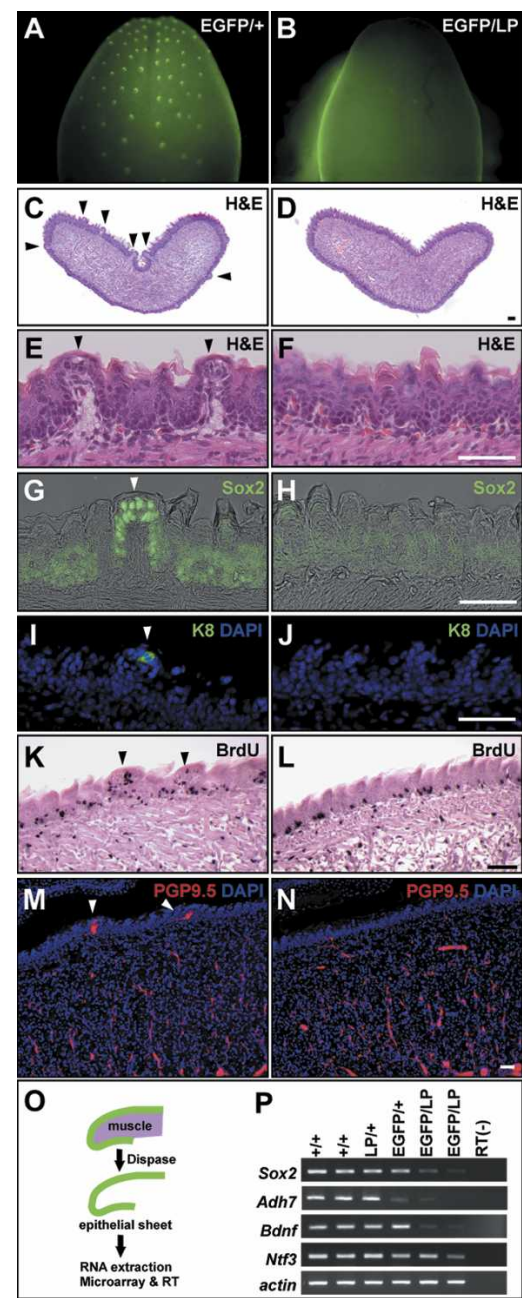

Figure 2. Phenotype of Sox2 hypomorphic mutant tongue. All samples are P0 except $K$ and $L$. EGFP expression in Sox $2^{E G F P /+}(A)$ and $\operatorname{Sox} 2^{E G F P / L P}(B)$ tongues. Histological sections of Sox $2^{+/+}(C, E)$ and Sox $2^{E G F P / L P}(D, F)$ tongues stained with hematoxylin and eosin (H\&E). Note the well-formed fungiform papillae in wild type (arrowheads) and their absence in mutant. (G) Immunostaining of wildtype tongues shows high Sox2 expression in TBs and lower levels in keratinocytes. $(H)$ In Sox $2^{E G F P / L P}$ tongues, only very low levels are seen in the keratinocytes. Antibodies to K8 reveal positive cells in wild-type TBs $(I)$, but no staining in $\operatorname{Sox} 2^{E G F P / L P}$ tongues $(J)$. BrdU staining of $\operatorname{Sox}^{+/+}(K)$ and $\operatorname{Sox} 2^{E G F P / L P}(L)$ embryos at E18.5 after a 1-h pulse fails to detect a significant change in cell proliferation. Innervation of $\operatorname{Sox} 2^{+/+}(M)$ and $\operatorname{Sox} 2^{E G F P / L P}(N)$ tongues as revealed by staining for PGP9.5. Arrowheads show fungiform papillae. (O) To isolate total RNA from epithelial cells free of mesoderm, tongues were treated with dispase for $30 \mathrm{~min}$ at $37^{\circ} \mathrm{C}$. $(P)$ RT-PCR analysis of Sox2, Adh7, Bdnf, and Ntf3 in epithelial cell RNA. Actin is internal control. Bars, $50 \mu \mathrm{m}$. 
2I), albeit at lower levels than in older animals, but no signal could be detected in Sox2 mutants (Fig. 2J).

Histological analysis also showed a deficiency of TBs in the mutant palate at P0 $(46 \pm 5.3$ TBs per palate in wild type vs. $5 \pm 0.6$ for mutants; $p<0.001$ ) (Supplementary Fig. 3). Palate TBs are not organized into domelike fungiform papillae. Their absence therefore suggests that Sox2 does not function only to promote the support cells of the fungiform papillae but is also required for the development of TB sensory cells and their progenitors.

We asked whether the reduction in Sox 2 in hypomorphic mutants also affects the differentiation of the keratinocyte lineage of the tongue. Significantly, no abnormalities were seen in the histology of filiform papillae at any stage nor in the proliferation of mutant and wildtype epithelial cells, as judged by labeling E16.5 and E18.5 embryos in utero with BrdU for $1 \mathrm{~h}$ (Fig. 2K,L; Supplementary Fig. 2). There was no increased apoptosis in the mutant tongues using antibody to cleaved caspase-3 (data not shown). Taken together, these findings support the idea that high Sox 2 is preferentially required for promoting the fate of the TB cells per fungiform papillae compared with keratinocytes.

We considered the possibility that the defects in TB development in hypomorphic embryos are caused by a failure in the innervation of the sensory cells rather than their specification. However, sections of P0 tongue and palate with antibody to PGP9.5, a marker for nerve fibers, showed no defects in the number and distribution of nerves in the mutants (Fig. 2M,N; Supplementary Fig. 3). These results support the idea that the regulation of TB development by Sox 2 is independent of gustatory innervation at the embryonic stage. This conclusion is consistent with the previous observation that mice null for $\operatorname{trk} B$, a receptor for $B d n f$, show normal development of fungiform papillae and TBs in spite of a severe reduction in the geniculate ganglion neurons that normally innervate these structures (Fritzsch et al. 1997).

\section{Gene expression in wild-type and mutant tongues}

To survey which Sox genes are expressed in the developing tongue, and to begin to identify candidate target genes for Sox2, we carried out microarray analysis. First, we compared gene expression between whole tongues at E13.5 (when fungiform placodes have just formed) and P0 (when TBs have differentiated). This showed that only Sox2 is expressed at high levels in the tongue at both stages. Transcripts for Sox7, Sox10, and Sox17 were present at low levels at E13.5, while the other Sox genes were undetectable. We therefore conclude that Sox2 is the major Sox family member expressed in the developing tongue.

To identify candidate Sox2 target genes we examined gene expression at $\mathrm{P0}$ in tongue epithelial cells free of mesoderm (Fig. 2O). Microarray analysis revealed several genes that are significantly changed (more than twofold) in Sox $2^{E G F P / L P}$ epithelium compared with wild type (Supplementary Table 1). For example, Sox2 itself is down-regulated (3.5-fold), a finding confirmed by RTPCR (Fig. 2P). Alcohol dehydrogenase 7, a key regulator of retinoic acid synthesis in the endoderm, is significantly decreased (5.2-fold) as is retinol dehydrogenase (5.8-fold), Nima-related expressed kinase 6 (4.1-fold), and Nischarin (3.8-fold). Bdnf, which is expressed in tongue epithelium and developing TB cells, and Ntf3, which encodes a neurotrophin normally expressed in the epithelial cells immediately surrounding the TBs, were not scored in the microarray analysis. However, RTPCR analysis showed significant reduction of both genes in hypomorphic mutants (Fig. 2P). Previous studies have demonstrated that $B d n f$-null mice have fewer fungiform papilla than normal, and Bdnf and Ntf4 double-mutant mice have a more severe reduction (Mistretta et al. 1999; Nosrat et al. 2004). Since the phenotype of Sox2 hypomorphic mutants is even more severe still, it is likely that Sox2 lies upstream of these and potentially other neurotrophic factors.

\section{Transgenic overexpression of Sox2 in the basal epithelium}

For gain-of-function studies we generated transgenic embryos in which Sox2 is expressed at high levels throughout the basal epithelium under the control of the keratin 5 (K5) promoter (Fig. 3A-C). A striking feature of the transgenic phenotype (Fig. 3D,E) was the complete absence of well-differentiated filiform papillae expressing trichohyalin, AE15 (Fig. 3F,G). In contrast, the epithelium was arranged in many small, papilla-like domes. Although these resembled fungiform papillae, staining with antibody to K8 was negative (data not shown). There was no significant increase in cell proliferation in transgenic tongues (Fig. 3H,I), and BrdU-labeled cells were distributed throughout the epithelium and not confined to the basal layer and top of fungiform papillae. These results support the idea that the expression of high levels of Sox2 throughout the basal layer inhibits the

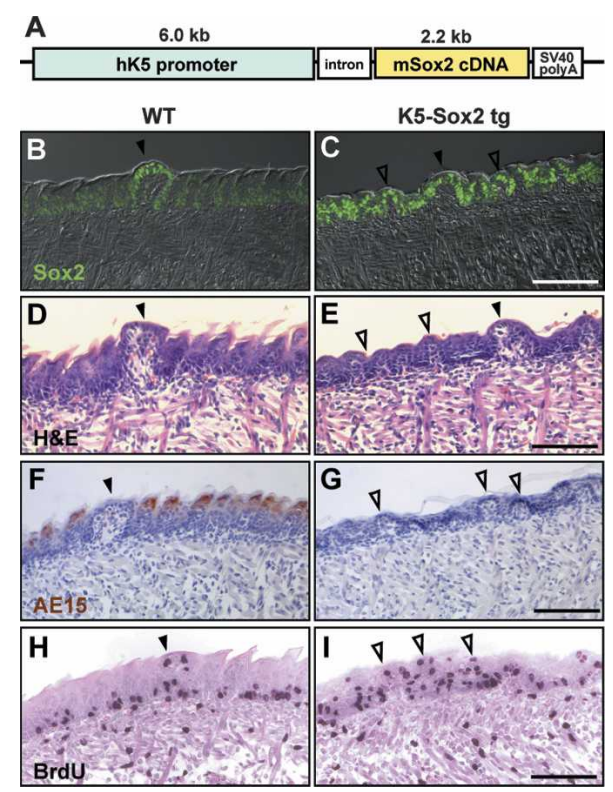

Figure 3. Phenotype of K5-Sox2 transgenic tongues. (A) Schematic of Sox 2 expression vector. $(B-I)$ Sections of E18.5 tongues with fungiform papillae marked by closed arrowheads. $(B, C)$ Transgenic expression of Sox 2 throughout the basal layer confirmed by immunohistochemistry. Histology shows multilayered, keratinized filiform papillae expressing AE15 in wild type $(D, F)$ but absence in mutant $(E, G)$. Instead, mutant tongues have many small, domed papilla-like structures (E, open arrowheads). BrdU-labeled cells are confined to basal layer and top of fungiform papillae in wild type $(H)$, but a less ordered distribution in transgenic $(I)$. Bars, $50 \mu \mathrm{m}$. 
morphogenesis and differentiation of filiform keratinocytes. However, in the absence of K8 staining, we have no evidence that high Sox 2 expression is sufficient to drive the development of ectopic TBs in transgenic tongues.

\section{Evidence that canonical Wnt signaling regulates Sox2 expression and TB development}

Little is known about how TB placode development is initiated and maintained in a specific pattern on the dorsal surface of the tongue. Previous studies have shown that Bmp4 and Shh are expressed in the placodes at E13E14 (Hall et al. 2003; Liu et al. 2004). However, their expression declines later. To identify other signaling pathways, we interrogated the microarrays comparing gene expression at E13.5 and P0. This revealed the expression at both stages of components of the Wnt signaling pathway (Supplementary Fig. 4A). For example, Wnt5b and Wnt6 transcripts are present at E13.5, but levels decline slightly at P0 (6.5- and 2.6-fold higher at E13.5 than P0). In contrast, Wnt4 and Wnt10a levels are increased at P0. We confirmed the expression for Wnt6 by RT-PCR (Supplementary Fig. 4B). Secreted frizzled related protein 2 (Sfrp2), encoding a potent antagonist of Wnt signaling, is also higher in E13.5 tongues. Among Tcf/Lef family members, Lef1 is highly expressed in the tongue epithelium while Tcf7 is at lower levels (Supplementary Fig. 4A).

In the ectoderm, canonical Wnt signaling plays a central role in hair follicle development (Huelsken et al. 2001). If Wnt signaling in the epidermis is blocked by the antagonist dikkopf-1, no hair follicle placodes are formed (Andl et al. 2002). Recent studies also indicate that Wnt signaling drives Sox2 expression in the developing retina (Van Raay et al. 2005). We therefore asked whether Wnt signaling regulates Sox 2 expression during tongue development. Significantly, there is strong expression of the canonical Wnt reporters, BAT-gal and TOP-gal (DasGupta and Fuchs 1999; Maretto et al. 2003), as well as elevated Sox2, in the sites of placode development at E12.5-E17.5 (Fig. 4A-D). $\beta$-Gal activity gradually declines at E18 to P0 but is still detectable at low levels in P5 TBs (Fig. 4F) and adult fungiform papillae (P15-P60) (Fig. 4I). Signal is not seen in vallate papilla until E14 but becomes stronger at E17.5 and remains until at least P30 (Fig. 4D,E; data not shown). In addition, whole-mount and section immunostaining of E13.5 tongues showed that levels of $\beta$-catenin, a transcriptional component of the canonical Wnt signaling pathway, are higher in placodes compared with neighboring epithelial cells, with the protein localized both in the membrane and the nucleus at E16.5 (Fig. 4K). Finally, we determined by in situ hybridization that Wnt6, encoding a candidate ligand for the canonical pathway, is specifically expressed in the epithelial layer at E13.5 (Fig. 4M, ${ }^{\prime}$ ). Taken together, these results provide strong evidence that canonical Wnt signaling is active in the tongue epithelium and promotes TB development and maintenance.

To determine whether canonical Wnt signaling is upstream of or downstream from Sox2, we cultured E13.5 Sox $2^{\mathrm{EGFP} /+}$ tongues under conditions in which EGFP expression is maintained in the papillae for $>2 \mathrm{~d}$. If $\mathrm{LiCl}(40$ $\mathrm{mM}$ ), a GSK3 $\beta$ inhibitor, is added to the medium at the start of the culture period, the intensity and extent of EGFP expression in the placodes is significantly enhanced compared with controls incubated with $\mathrm{NaCl}$ (40



Figure 4. $(A-I)$ Canonical Wnt signaling and TB development. LacZ expression in BAT-gal reporter embryos. $(A)$ Tongue at E12.5. $(B)$ Section of E13.5 tongue. $(C)$ Tongues at E14.5. (D) Tongue at E17.5. (E) Tongue at P5. (F) Section of P5 fungiform. (G) Section of P5 vallate papilla. $(H)$ Whole palate at P5. (I) Section of fungiform papilla at P60. (J) Expression of $\beta$-catenin in tongue at E13.5. Immunostaining for $\beta$-catenin in E16.5 tongue $(K)$, and P0 fungiform papilla $(L)$. Nuclei are counterstained with DAPI. Expression of Wnt6 in E13.5 tongue by whole-mount in situ hybridization $(M)$ and after sectioning $\left(\mathrm{M}^{\prime}\right)$. Organ culture of E13.5 Sox $2^{E G F P /+}$ tongue. EGFP expression after $2 \mathrm{~d}$ treatment with $40 \mathrm{mM} \mathrm{NaCl}(N, O, P)$ or $\mathrm{LiCl}$ $(Q, R, S)$. Note significant up-regulation of EGFP expression after $\mathrm{LiCl}$ treatment. Dorsal $(N, Q)$ and frontal $(O, R)$ view of the cultured tongues. $(P, S)$ Expression of $\beta$-catenin. Nuclei were counterstained with DAPI. Bars, $30 \mu \mathrm{m}$.

$\mathrm{mM}$ ) (Fig. 4N,Q). An increase is seen after $24 \mathrm{~h}$, the earliest time examined. There are also patches of ectopic EGFP expression between placodes and in the ventral epithelium (Fig. 4O,R) and stronger EGFP expression in the vallate papilla (data not shown). Consistently, $\beta$-catenin accumulation was seen in the LiCl- but not $\mathrm{NaCl}$-treated tongues (Fig. 4P,S). Weak enhancement of EGFP by LiCl was still seen in E15.5 tongues, but the effect was lost by E17.5 (Supplementary Fig. 5). We interpret these results to mean that tongue epithelial cells differentially respond to Wnt signaling during development. Since forced Wnt signaling can activate Sox2 expression in nonplacode epithelial cells at E13.5, these cells may still be bipotential, with the ability to differentiate into either TB (fungiform) cells or keratinocytes (filiform). However, by later stages (E16-E18) the interplacode cells are already committed to the keratinocyte lineages and so do not show ectopic Sox2 expression. 


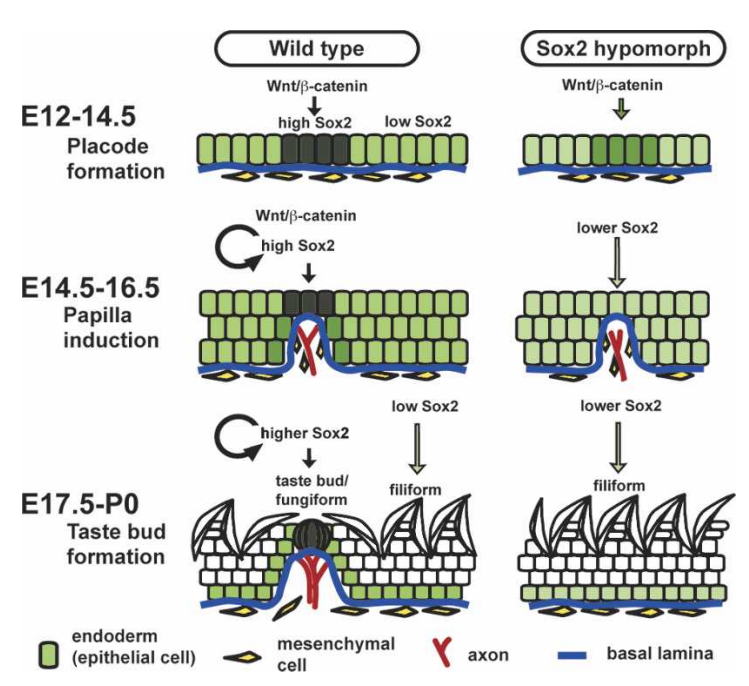

Figure 5. A model for the roles of Sox2 in TB development. (Left panels) Normal development. (Right panels) Defective development in hypomorpic mutants. During placode formation stage (E12-E14), localized clusters of tongue epithelial cells express high Sox2 activated by canonical Wnt signaling. During papilla induction stage (E14-E16), the high Sox2-expressing placode cells subsequently form fungiform papillae where Wnt signaling is still active. Concomitantly there is migration of mesenchymal cells and nerves into the center of the papilla. During the TB formation stage (E17 to P0) high Sox2-expressing cells finally differentiate into TB cells, and sensory cells become innervated. In contrast, low Sox2-expressing cells normally differentiate into the keratinocytes of filiform papillae. In Sox2 hypomorphic mutants, tongue epithelial cells have lower expression of Sox 2 and cannot differentiate into TB cells.

\section{Model for the dose-dependent regulation of TB development by Sox2}

Taken together, our gain-of-function and loss-of-function data provide the first evidence that Sox 2 is critical for the development and maturation of TB sensory cells from endodermal progenitor cells of the tongue. Moreover, our results suggest that canonical Wnt signaling functions in a stage-specific and dose-dependent manner both for TB development and for the maintenance of mature TBs postnatally. According to our model (Fig. 5), localized canonical Wnt signaling is first needed at the placode-forming stage to up-regulate Sox2 and to preferentially segregate future TB cells versus keratinocyte precursors from bipotential tongue endoderm progenitors. In the epidermis of the skin, the Wnt $/ \beta$-catenin pathway is known to be important for promoting the hair follicle lineage (Gat et al. 1998; Huelsken et al. 2001; Silva-Vargas et al. 2005). Similarly, our results suggest that the Wnt $/ \beta$-catenin-Sox 2 axis functions in putative progenitor cells of the tongue to drive cell fate decisions toward the TB lineage. Once TB placodes are formed as high Sox2-expressing clusters, two mechanisms may sustain their identity and promote their differentiation into mature TB cells by maintaining high Sox 2 expression. First, Sox 2 expression may be autoregulated by Sox2 itself, as shown in human embryonic stem (ES) cells (Boyer et al. 2005). Second, Wnt signaling may continue to maintain Sox2 expression since the activity of BAT-Gal and TOP-Gal reporters continues in adult TBs. In support of the idea that Sox2 is a direct target for Wnt signaling, recent studies have identified potential TCF/ LEF-binding sites in some of the multiple Sox2 enhancer regions that are conserved between vertebrate species (Uchikawa et al. 2003; Takemoto et al. 2006).

Sox2-null mutant embryos die around implantation (Avilion et al. 2003). Sox $2^{E G F P / L P}$ compound hypomorphic mutants overcome this early embryonic lethality but develop specific abnormalities later. This suggests that different tissues, including sensory organs and TB progenitors, have different dose dependencies for Sox2. It is also possible that the PGK-neo cassette inserted into the $3^{\prime}$ region of the hypomorphic allele preferentially disrupts a tissue-specific enhancer required in these tissues. This idea is supported by studies showing the presence of multiple tissue-specific enhancers in both mouse and chick Sox2 (Uchikawa et al. 2003; Kiernan et al. 2005). However, confirmation of this idea must await identification of the enhancer(s) driving expression in the tongue and TBs.

Extending our findings further, it will be of interest to see whether mutations in human SOX2 that cause anophthalmia, hearing loss, and esophageal atresia (Hagstrom et al. 2005; Williamson et al. 2006), are also associated with defects in the taste sensory system. Finally, unlike the nerve cells of the adult mammalian eye and cochlea, which cannot regenerate, TB cells normally turn over in adulthood every 10-14 d. They can also regenerate after gustatory nerve injury and irradiation therapy. It will therefore be of great interest to further study the role of Sox2 in TBs as an adult stem cell model system.

\section{Materials and methods}

Mice

Sox $2^{E G F P /+}$ and Sox $2^{L P /+}$ mice were made as described (Taranova et al. 2006). The latter has a PGK-Neo cassette flanked by a loxP site in the $3^{\prime}$ region of the locus. BAT-gal and TOP-gal mice were kindly provided by Stefano Piccolo and Elaine Fuchs, respectively. Mouse Sox2 cDNA was cloned into an expression vector containing a basal cell-specific 6-kb human K5 promoter (Byrne and Fuchs 1993) and transgenic embryos generated by pronuclear injection. Eight transgenic embryos were analyzed in detail.

Tissue preparation and immunostaining

Tongues were fixed in $4 \%$ paraformaldehyde and embedded in paraffin, and $7-\mu \mathrm{m}$ sections were stained with the following antibodies: $\beta$-catenin (clone 14, Transduction Laboratory), K8 (Troma-I; Developmental Studies Hybridoma Bank, University of Iowa), AE15 (kindly provided by Tung-Tien Sun), BrdU (clone BU-33, Sigma), PGP9.5 (Dako), and Sox2 (Taranova et al. 2006).

\section{In situ hybridization}

Mouse Wnt6 cDNA was kindly provided by Saverio Bellusci and was originally from Andrew McMahon. In situ hybridization analysis was performed by standard procedures.

\section{$R T-P C R$}

Total RNA was extracted by RNeasy (Qiagen) and cDNA synthesized by SuperScript First Strand Synthesis Kit (Invitrogen) from $1 \mu \mathrm{g}$ total RNA. Primer sets were Sox2 (AACGGCTCGCCCACCTACAGC, CAGG GGCAGTGTGCCGTATTTGG), Bdnf (CACAGTCCTAGAGAAAGTCC, AATGGTCAGTGTACATACAC), Ntf3 (ATCAAAACCGGTAACTC TCC, GCACACACACAGGAAGTGTC), Adh7 (TCCAGGATCATTGGAATCGAC, CTCAAAATGTCAGGACAGTCC), and actin (GTCGTACCACAGGCATTGTGATGG, GCAATGCCTGGGTACATGGTGG).

\section{Organ culture}

Sox $2^{E G F P /+}$ tongues were washed four times in DMEM/F12 medium (Cellgro catalog no. 30-2006) and incubated on 8- $\mu \mathrm{m}$ pore filters (Becton Dickinson catalog no. 35-3182) in DMEM/F12 with $1 \%$ fetal bovine se- 
rum, B-27 supplement (Gibco), and penicillin/streptomycin (Sigma) at $37^{\circ} \mathrm{C}$ for $2 \mathrm{~d}$.

\section{Microarray}

Microarray analysis was performed using the Operon Mouse Genome Oligo Set version 3.0. Total RNA (500 ng) was amplified with one round MessageAmp TM aRNA Amplification kit (Ambion). Genespring 6.1 was used for data analysis. Procedures are described in detail at http:// microarray.genome.duke.edu/spotted-arrays/protocols.

\section{Acknowledgments}

We thank Holly Dressman of the Duke Microarray Facility for her advice and Tannishtha Reya for critical discussion of the manuscript. This work was supported by NIH grant HL071303.

\section{References}

Andl, T., Reddy, S.T., Gaddapara, T., and Millar, S.E. 2002. WNT signals are required for the initiation of hair follicle development. Dev. Cell 2: 643-653.

Avilion, A.A., Nicolis, S.K., Pevny, L.H., Perez, L., Vivian, N., and LovellBadge, R. 2003. Multipotent cell lineages in early mouse development depend on SOX2 function. Genes \& Dev. 17: 126-140.

Beidler, L.M. and Smallman, R.L. 1965. Renewal of cells within taste buds. J. Cell Biol. 27: 263-272.

Boyer, L.A., Lee, T.I., Cole, M.F., Johnstone, S.E., Levine, S.S., Zucker, J.P., Guenther, M.G., Kumar, R.M., Murray, H.L., Jenner, R.G., et al. 2005. Core transcriptional regulatory circuitry in human embryonic stem cells. Cell 122: 947-956.

Byrne, C. and Fuchs, E. 1993. Probing keratinocyte and differentiation specificity of the human K5 promoter in vitro and in transgenic mice. Mol. Cell. Biol. 13: 3176-3190.

DasGupta, R. and Fuchs, E. 1999. Multiple roles for activated LEF/TCF transcription complexes during hair follicle development and differentiation. Development 126: 4557-4568.

Delay, R.J., Kinnamon, J.C., and Roper, S.D. 1986. Ultrastructure of mouse vallate taste buds: II. Cell types and cell lineage. J. Comp. Neurol. 253: 242-252.

Fritzsch, B., Sarai, P.A., Barbacid, M., and Silos-Santiago, I. 1997. Mice with a targeted disruption of the neurotrophin receptor trkB lose their gustatory ganglion cells early but do develop taste buds. Int. J. Dev. Neurosci. 15: 563-576.

Gat, U., DasGupta, R., Degenstein, L., and Fuchs, E. 1998. De novo hair follicle morphogenesis and hair tumors in mice expressing a truncated $\beta$-catenin in skin. Cell 95: 605-614.

Hagstrom, S.A., Pauer, G.J., Reid, J., Simpson, E., Crowe, S., Maumenee, I.H., and Traboulsi, E.I. 2005. SOX2 mutation causes anophthalmia, hearing loss, and brain anomalies. Am. J. Med. Genet. A 138: 95-98.

Hall, J.M., Bell, M.L., and Finger, T.E. 2003. Disruption of sonic hedgehog signaling alters growth and patterning of lingual taste papillae. Dev. Biol. 255: 263-277.

Huelsken, J., Vogel, R., Erdmann, B., Cotsarelis, G., and Birchmeier, W. 2001. $\beta$-Catenin controls hair follicle morphogenesis and stem cell differentiation in the skin. Cell 105: 533-545.

Kiernan, A.E., Pelling, A.L., Leung, K.K., Tang, A.S., Bell, D.M., Tease, C., Lovell-Badge, R., Steel, K.P., and Cheah, K.S. 2005. Sox2 is required for sensory organ development in the mammalian inner ear. Nature 434: 1031-1035.

Knapp, L., Lawton, A., Oakley, B., Wong, L., and Zhang, C. 1995. Keratins as markers of differentiated taste cells of the rat. Differentiation 58: 341-349.

Liu, H.X., Maccallum, D.K., Edwards, C., Gaffield, W., and Mistretta, C.M. 2004. Sonic hedgehog exerts distinct, stage-specific effects on tongue and taste papilla development. Dev. Biol. 276: 280-300.

Lopez, G.F. and Krimm, R.F. 2006. Epithelial overexpression of BDNF and NT4 produces distinct gustatory axon morphologies that disrupt initial targeting. Dev. Biol. 292: 457-468.

Maretto, S., Cordenonsi, M., Dupont, S., Braghetta, P., Broccoli, V. Hassan, A.B., Volpin, D., Bressan, G.M., and Piccolo, S. 2003. Mapping Wnt $/ \beta$-catenin signaling during mouse development and in colorectal tumors. Proc. Nat1. Acad. Sci. 100: 3299-3304.
Mistretta, C.M. 1998. The role of innervation in induction and differentiation of taste organs: Introduction and background. Ann. N. Y. Acad. Sci. 855: 1-13.

Mistretta, C.M., Goosens, K.A., Farinas, I., and Reichardt, L.F. 1999 Alterations in size, number, and morphology of gustatory papillae and taste buds in BDNF null mutant mice demonstrate neural dependence of developing taste organs. J. Comp. Neurol. 409: 13-24.

Nosrat, I.V., Agerman, K., Marinescu, A., Ernfors, P., and Nosrat, C.A. 2004. Lingual deficits in neurotrophin double knockout mice. J. Neurocytol. 33: 607-615.

Potten, C.S., Al-Barwari, S.E., Hume, W.J., and Searle, J. 1977. Circadian rhythms of presumptive stem cells in three different epithelia of the mouse. Cell Tissue Kinet. 10: 557-568.

Silva-Vargas, V., Lo Celso, C., Giangreco, A., Ofstad, T., Prowse, D.M. Braun, K.M., and Watt, F.M. 2005. $\beta$-Catenin and Hedgehog signal strength can specify number and location of hair follicles in adult epidermis without recruitment of bulge stem cells. Dev. Cell 9: 121131.

Takemoto, T., Uchikawa, M., Kamachi, Y., and Kondoh, H. 2006. Convergence of Wnt and FGF signals in the genesis of posterior neural plate through activation of the Sox 2 enhancer N-1. Development 133: 297-306.

Taranova, O.V., Magness, S.T., Fagan, B.M., Wu, Y., Surzenko, N., Hutton, S.R., and Pevny, L.H. 2006. SOX2 is a dose-dependent regulator of retinal neural progenitor competence. Genes \& Dev. 20: 11871202.

Uchikawa, M., Ishida, Y., Takemoto, T., Kamachi, Y., and Kondoh, H. 2003. Functional analysis of chicken Sox2 enhancers highlights an array of diverse regulatory elements that are conserved in mammals. Dev. Cell 4: 509-519.

Van Raay, T.J., Moore, K.B., Iordanova, I., Steele, M., Jamrich, M., Harris, W.A., and Vetter, M.L. 2005. Frizzled 5 signaling governs the neural potential of progenitors in the developing Xenopus retina. Neuron 46: 23-36.

Williamson, K.A., Hever, A.M., Rainger, J., Rogers, R.C., Magee, A., Fiedler, Z., Keng, W.T., Sharkey, F.H., McGill, N., Hill, C.J., et al. 2006. Mutations in SOX2 cause anophthalmia-esophageal-genital (AEG) syndrome. Hum. Mol. Genet. 15: 1413-1422. 


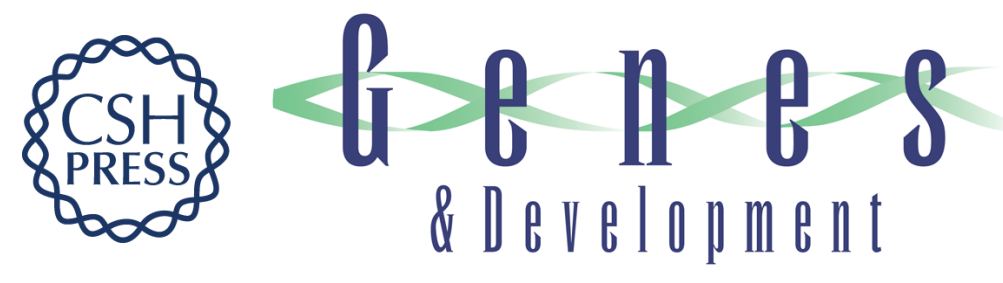

\section{Sox2 is required for development of taste bud sensory cells}

Tadashi Okubo, Larysa H. Pevny and Brigid L.M. Hogan

Genes Dev. 2006, 20:

Access the most recent version at doi:10.1101/gad.1457106

Supplemental

Material

References

This article cites 27 articles, 7 of which can be accessed free at:

http://genesdev.cshlp.org/content/20/19/2654.full.html\#ref-list-1

\section{License}

Email Alerting Service

http://genesdev.cshlp.org/content/suppl/2006/09/19/20.19.2654.DC1 right corner of the article or click here.

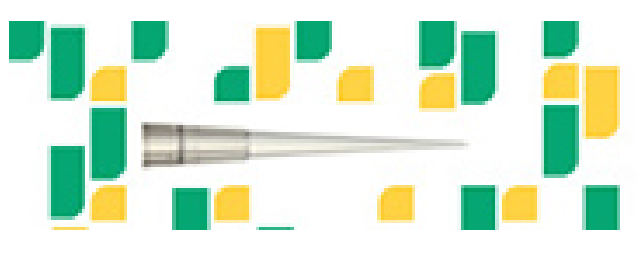

Focused on your science. 